\title{
Institutional Settings and their Impact on the IPO Activity: An Exploratory Study Based on Qualitative Modelling
}

\author{
Tomáš Meluzín, Marek Zinecker, Adam P. Balcerzak, \\ Michał B. Pietrzak, Karel Doubravský
}

Brno University of Technology, Faculty of Business and Management, Antonínská 548/1, 61090 Brno, Czech Republic, meluzint@fbm.vutbr.cz, zinecker@fbm.vutbr.cz, doubravsky@fbm.vutbr.cz

University of Warmia and Mazury in Olsztyn, Faculty of Economic Sciences, ul. pl. Cieszyński 1/327; 10-720 Olsztyn, Poland; Brno University of Technology, Kolejní 2906/4, 61200 Brno, Czech Republic, a.balcerzak@uwm.edu.pl

Nicolaus Copernicus University, Faculty of Economic Sciences and Management, ul. Gagarina 13a, 87-100 Toruń, Poland, michal.pietrzak@umk.pl

\begin{abstract}
This article deals with the propagation of rumours about the introduction of institutional settings, which are intended to make the going public strategy in a country more attractive. Rumours significantly affect the level of uncertainty and can be both positive - if the market responds by increasing the initial public offering activity - or negative - if the market responds by a drop of primary issues. We document how the going public activity in a country might be promoted if both positive and negative rumours occur. The rumour spreading model called SIRaRu and qualitative trend-based modelling are applied. There are no quantifiers such as numbers or fuzzy sets needed. Altogether 17 variables are used to capture two dimensions of general institutional quality and internal state of the company. The numerical calculations result in a set $S$ of 9 scenarios, which are complemented by a set $T$ of 46 transitions. Hence, any past and future behaviour of the qualitative model QS can be reconstructed as a sequence of obtained scenarios. Moreover, a graphic solution was derived to study the behaviour of selected variables on the timeline.
\end{abstract}

Keywords: institutional economics; rumours; IPO; qualitative trend models; scenarios

\section{Introduction}

An initial public offering (IPO) represents a procedure within which a firm sells common stocks to the investment public for the first time since its establishment. It is a milestone in the business life cycle providing shareholders and investors 
interested in buying shares a unique opportunity of making a profit on their investment (Certo et al. 2009). Going public activity in a country is in general interpreted as a favourable dimension of overall-economic development supporting investments, growth, and job creation (Lewellyn and Bao 2014). Many academic studies emphasize the essential role of a well-developed financial system, where such institutions are established, which mobilise savings, accelerate the capital flow, and optimise capital allocation (Olgic Draženovic and Kusanovic 2016).

Lewellyn and Bao (2014) suggest that the parties involved in the going public procedure require a certain degree of certainty in achieving their individual interests. There are two categories of institutions lowering the level of uncertainty, i.e. affecting the belief of market participants that the valuation of the corporate stocks will be well-balanced and that any profits will be secured from "wrongful misappropriation" (Lewellyn and Bao 2014). Firstly, formal institutions have to be established, i.e. laws and regulations protecting minority shareholders from oppressive or unfairly prejudicial behaviour by controlling shareholders, stable and in its operations efficient and transparent government, stable political regime, zero corruption, public access to information, and integrity of the judiciary (e.g. La Porta et al. 2006, 1997). Moreover, as Lewellyn and Bao (2014) note, the institutional environments taking impact on the IPO activity in a country are also "composed of informal institutions". These institutions include local (often religious) norms, taboos, traditions, customs, and the perception of humility, patience, curiosity, openness, and independent thinking (Boetke et al. 2008). Recent empirical research delivered evidence that national or local culture could play a significant role in encouraging or impeding IPO activity" (Lewellyn and Bao 2014).

In this paper, we build on our previous works devoted to the spreading of rumours related to political or macroeconomic instability and their impact on going public activity in a country (Meluzín et al. 2018). More specifically, we study the link between rumours about the introduction of institutional settings, which might reduce political uncertainty and boost the IPO activity in an emerging capital market. Empirical evidence suggests a positive correlation between the institutional quality on local stock markets and IPO volumes (Lewellyn and Bao 2014, La Porta et al. 1997, King and Levine 1993). We use an explorative research approach based on qualitative modelling and the rumour spreading model SIRaRu introduced by Wang et al. (2014). This model investigates the dynamics of rumours which are spread in complex social networks. We study how the going public volumes in a country might be promoted if positive rumours in regard to the introduction of institutional settings occur. This might happen during election campaigns or if a new government is appointed into office. The SIRaRu model is designed on a qualitative basis; this means that there is information shortage in relation to the impact of institutions on the IPO activity and this is obtainable only as a verbal description based on prior knowledge of the trend. We define specific 
stock market conditions on prior rumour spreading models and derive a new qualitative model based on heuristics. A transitional graph is used as a tool to cover all possible past and future behaviour of the variables under study. Furthermore, a graphic solution was derived to study the behaviour of selected variables on the timeline. To our knowledge, this study contributes to the existing body of the going public literature as the relationship between the various aspects of formal institutions and going public volumes has not yet been studied on a qualitative basis. This research approach is used because a shortage of data makes an application of conventional statistical methods not possible. We believe that the results represent a tool supporting IPO companies, investors, and public authorities in their decision making if rumours occur and thus conceivable scenarios of the subsequent developments have to be analysed and evaluated.

The remainder of this article is structured as follows. Section 2 deals with the literature on institutional settings and their impact on the IPO activity with a focus on emerging markets. In Section 3, data and methods are discussed. Section 4 presents the main research results. The discussion and conclusions are outlined in the last section.

\section{Theoretical Background}

The question to what extent expansion of the financial system contributes to overall-economic growth has been investigated extensively in financial academic literature for decades (Skare and Porada-Rochoń 2019, Karkowska and Kravchuk 2019, Olbryś 2019). King and Levine (1993) report that countries with marketbased financial systems can achieve higher economic growth in the long run. While banks as financial intermediaries lose importance, an increasing number of empirical studies have provided evidence that institutional investors and capital markets are becoming key elements accelerating capital raising and securities trading (Olgic Drazenovic and Kusanovic 2016; Meluzín et al. 2018; Bonaventura and Giudici 2017). This transformation is mainly driven by the globalisation and liberalisation facilitating capital inflows and outflows and accelerating capital market interconnections (Balcerzak and Pietrzak 2017). The volume of IPOs has accelerated during the last two decades in emerging markets and stock exchanges belong to essential elements that form the external business environment (Kisel'áková et al. 2019).

The academic theory dealing with IPOs has identified many factors that are relevant in terms of the going public activities. A significant number of studies are focused on microeconomic issues, such as making a decision on where to obtain financial resources and how to optimize a capital structure (Gombola et al. 2019, Pieloch-Babiarz, 2020, Kliestik, et al., 2020, Myers 1984), information disclosure (Hlel et al. 2020, Maksimovic and Pichler 2001, Chemmanur and Fulghiery 1999), 
broadening the ownership structure (Foley and Greenwood 2010, Boot et al. 2006) or fear of IPO failure (Fontinelle 2015). Approximately the same amount of literature documents, how different external factors affect the demand and supplyside on primary markets with public issues. The qualitative aspects of the institutional background is a crucial factor determining capital market efficiency (Olgic Drazenovic and Kusanovic 2016, Lewellyn and Bao 2014, La Porta et al. 2006, 1997, King and Levine 1993). The risk of external investors in terms of investments into primary shares arises from a lack of information about issuing firms and zero history of market pricing (Certo et al. 2009). There is also high uncertainty on the side of issuers who might be exposed to disinterest of investors resulting in the IPO failure. Doidge et al. (2012) and North $(2003,1990)$ argue that uncertainty can be reduced by an appropriate institutional framework pushing involved parties to keep on the rules of the game. In their groundbreaking studies, La Porta et al. $(2006,1997)$ document how the ownership structure, the quality of the protection of property rights, and the law enforcement quality affect local capital market developments and the volumes of IPOs. The authors show that common law countries provide investors with better protection of property rights than civil law countries, which is supported by the development of the local financial market institutions. From more recent studies delivering empirical evidence on the role of the institutional framework, we recall Lewellyn and Bao (2014) who analysed IPOs in 45 countries in the period between 2001 and 2011. They found that the level of IPO activity is positively influenced by the quality of formal institutions work in the country and the culture, which should be performance, oriented. Many other studies on emerging capital markets also reveal that volumes of primary issues is driven by changes in political and economic ecosystem in particular because more efficient general economic institutions lower the transaction cost, risk, and uncertainty and boost returns on investment (Doidge et al. 2012, Kaufman et al. 2009).

The institutional theory distinguishes between formal and informal institutions (North 2003, 1990). Helmke and Levitsky (2004) define formal institutions as "rules and procedures that are created, communicated, and enforced through channels widely accepted as official". By contrast, informal institutions are "socially shared rules, usually unwritten, that are created, communicated, and enforced outside of officially sanctioned channels". The theory suggests that formal and informal institutions within a country interact in various forms and both affect economic performance (Lewellyn and Bao 2014, Helmke and Levitsky 2004). However, while formal institutions can be modified depending on political preferences and overall economic conditions, informal institutions are rather resistant in terms of radical changes (Balcerzak, 2020). Helmke and Levitsky (2004) believe that informal institutions play an essential role in enforcing the formal rules. Therefore, establishing formal institutions is not a guarantee of their effective functioning as long as these institutions are not accepted by economic actors (Lizińska et al. 2016). 
The political system in a country and the state government are essential elements in shaping the formal institutional environment that is intended to define what rules in economic transactions will be followed and how the behaviour of economic actors - firms going public and investors - will be regulated (North 2003, 1990). Prior studies have shown that the ability of formal institutions to protect minority shareholders has a strong and positive impact on the IPO volumes, as these regulations define barriers to insiders or majority shareholders to expropriate profits or assets from companies (Djankov et al. 2008, La Porta et al. 2006, 1997). As noted by Lewellyn and Bao (2014), law enforcement is as important as legal protection because investors evaluate both the "level of law" and "order," generally known as the "rule of law," which will take influence on systematic risk in a country and ultimately perceived risk of investments in primary shares.

The investors as well as the intra-firm decision-makers are very sensitive in terms of both formal and informal institutions and their development reflected, e.g. in government policies and campaigns as well as in terms of opinions, estimations or predictions evaluating such policies. Private analysts, columnists, or financial experts use countless information channels to convey information about governments, industries, and enterprises. Such estimations and opinions can be sometimes interpreted as rumours - "purely speculative and unreliable" information of all kinds with the potential to affect behaviours of economic actors substantially (Spiegel et al. 2010). The character of rumours can vary from a simple gossip to well-developed marketing propaganda. Nekovee et al. (2007) interpret rumours as an "infection of the mind" meaning that their transmitting documents a close similarity to that of epidemics. Chen and Kutan (2016), Spiegel et al. (2010), or Kosfeld (2005) document that rumours unambiguously have a psychological impact on the intra-firm decision-makers and external investors. The authors conclude that in particular high-tech information sources such as websites, social networks and blogs represent a kind of the "intellectual epidemic". Studying the transmission of "intelectual epidemics" has a long tradition. Goffman and Newill (1964) defined the "epidemic" process" as "transition from one state (susceptible) to another (infective) where the transition is caused by exposure to some phenomenon (infectious material)". Daley and Kendall (1964), who developed the very first rumour-spreading model, divided the closed and homogenously mixed population into three groups. The first group are spreaders (S), who attempt actively to "infect" the other individual with the rumours by pair-wise contacts. If the other individual is ignorant of the rumour (I), it turns into a spreader. The third group are those who already know the rumour and decide not to spread it anymore, hence they turn into stiflers (R). Wang et al. (2014) argue that rumour spreading differs from the transmission of infectious disease. While an infected patient is unable to take influence whether to spread the disease to others or not, an individual has the autonomy to perform an action, whether to accept the rumour and spread it or not. They accept enlarged classification of stiflers proposed by Huang and Jin (2011). "Ra" stands for 
individual "who accept the rumour but lose interest to spread it". "Ru" are people who do not accept the rumour at all. Furthermore, Wang et al. (2014) attempted to overcome a traditional shortcoming of the above class of models that assume a homogeneously mixing population. The SIRaRu rumour-spreading model extends the research while describing the dynamics of rumours in "complex networks" and delivers evidence that "the spreading threshold exists in both homogenous and inhomogeneous networks".

Summing up, we believe that the phenomenon of rumour propagation offer a unique opportunity for studying the variability in the number of IPOs across countries. Rumours significantly affect the level of uncertainty and can be both positive - if the market responds by increasing the initial public offering activity or negative - if the market responds by a drop of primary issues. Hence, to better understand the impact of rumours on the IPO activity, we hypothesize that rumours about the introduction of stronger institutional settings driven by political and economic changes will help to foster IPO activity in a country, however, the success of an individual firm might be seriously jeopardized by misinformation and rumours related to a range of intra-firm issues. We adopt the SIRaRu rumourspreading model introduced by Wang et al. (2014) and tools of qualitative modelling to examine the above hypothesis with a focus on emerging primary stock markets.

\section{Methodology}

\section{Qualitative Trend Models and Transitional Graphs}

Studying the impact of rumours on the IPO activity is a task that can be described as unique, non-linear, (partially) subjective, and vague. Generally, the key problem of realistic and complex tasks is a serious lack of information (Doubravsky and Dohnal 2018). This limits the straightforward application of traditional statistical methods assuming the existence of complex data sets. Therefore, both objective and subjective information require synthesis to obtain the obvious benefits of objective accuracy (deep knowledge) and semi-subjective common sense capabilities (shallow knowledge) see, e.g. Jiang et al. (2014).

A shallow knowledge item is represented by heuristics or statistical data sets. It is usually characterized by a number of exceptions. Shallow knowledge/data sets items have forms of equations as well. Exponential or polynomial relations are typical examples. The larger part of shallow knowledge items takes the form of a mere verbal description based on pairwise trends, decreasing, constant and increasing (Yan et al. 2013). The most common examples of such pairwise trend relations can be seen in Figure 1. All pair-wise relations X, Y are based on trends. It means no quantifiers are used. The pairwise trend relations are marked as 21 , 
$22,23,24,25$, and 26 and represent just an expression of the first quadrant of a coordinated system, for more details see (Doubravsky and Dohnal 2018). To design the trend model, deep knowledge, shallow knowledge, or both are applied. The trend model based on deep knowledge is denoted QR, the trend model based on shallow knowledge is denoted $\mathrm{QH}$, and the trend model based on both knowledge is denoted QS. Qualitative variables and constants are used in all of the mentioned models.

The trend model based on deep knowledge is defined as a set of differential equations. This model is denoted:

$\mathrm{QR}(\mathrm{X})$

Where $\mathrm{X}=(\mathrm{X} 1, \mathrm{X} 2, \ldots, \mathrm{Xn})$ is a vector of monitored variables of qualitative type.
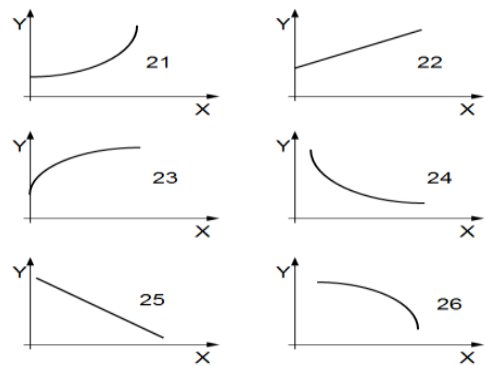

Figure 1

Qualitative pair wise relations - the most common examples

The trend model (1) is identified when all monitored variables $\mathrm{X} 1, \mathrm{X} 2, \ldots, \mathrm{Xn}$ are specified by triplets:

(Xi, DXi, DDXi), i = 1, 2,.., n

Where DX is the first qualitative time derivative of $\mathrm{X}$ and DDX is the second qualitative time derivative of the variable $X$.

Let give the following example: the triplet $(+++)$ means that the variable $\mathrm{X}$ takes only positive values $(X=(+))$, is growing over time $(\mathrm{DX}=(+))$ and this growth is of an accelerating nature (DDX $=(+)$ ). Hence, the solution of the model $\mathrm{QR}$ is a set MR comprising the triplets (2) which are in accordance with all equations of the model QR. An element $\mathrm{S}$ of the set MR is written as follows:

[(X1, DX1, DDX1), (X2, DX2, DDX2),.., (Xn, DXn, DDXn)].

Thus, each element of MR represents one particular solution of the model QR. This solution is called a scenario. The process of finding the solution MR of the model QR is called trend analysis, for more details see Doubravsky and Dohnal (2018). Each element of the triplet (2) can be substituted only by a finite volume of qualitative values. The set MR comprises only a finite volume of scenarios. 
Hence, within a trend analysis, a finite set of solutions can be obtained. In many real-world situations, equations are not available to describe the model. In such cases, the experience and knowledge of experts are used. The trend model based on shallow knowledge is provided by statements as follows:

$\mathrm{QH}(\mathrm{H} 1, \mathrm{H} 2, \ldots, \mathrm{Hw})$

Where $\mathrm{w}$ is the number of statements.

In order to work with the model, it is necessary to convert the statement into mathematical language. The easiest way how to conduct the conversion is the application of pairwise trends, see Figure 1. Each statement can be transferred to a pairwise trend:

$\operatorname{Pv}(X i, X j)$

Where $v=1,2, \ldots, w$ and $i, j=1,2, \ldots, n, i \neq j$.

The trend model (4) can be written using a pairwise trend:

$\mathrm{QH}(\mathrm{P} 1, \mathrm{P} 2, \ldots, \mathrm{Pw})$

In respect to (5) the model (6) can be written:

$\mathrm{QH}(\mathrm{X})$

Where $\mathrm{X}=(\mathrm{X} 1, \mathrm{X} 2, \ldots, \mathrm{Xn})$ is an expression of the vector of variables under study.

The output of the model $\mathrm{QH}$ is a set $\mathrm{MH}$ containing the triplets (2) which meet all pairwise trends (5). An element of the set $\mathrm{MH}$ is scenario (3). The mixed trend model QS is the model based on deep and shallow knowledge. The mixed trend model is created by merging (used the symbol - ) of equations with pairwise trends.

$\mathrm{QS}(\mathrm{X})=\mathrm{QR}(\mathrm{X})-\mathrm{QH}(\mathrm{X})$

The output of the model QS is a set MS of scenarios (3) which is the intersection of the set MR and $\mathrm{MH}$.

$\mathrm{MS}=\mathrm{MR} \cap \mathrm{MH}$.

From a set $\mathrm{M}$ of scenarios $\mathrm{S}$, transitions between these scenarios can be generated. The scenarios and the transitions between them can be represented by a transitional graph. An elementary common-sense analysis of an oscillator suggests that a spring that is rolling in one single way must be stopped in the first stage; in the second stage, it can be redirected. We can conclude that the next transition between two triplets which are one-dimensional is ruled out:

$(+++) \rightarrow(+--)$.

The transitional graph "G" consists of nodes representing the scenarios $S$. The set of the ordered pairs can be expressed as $\mathrm{T} \subseteq(\mathrm{S} \times \mathrm{S})$.

$\mathrm{G}(\mathrm{S}, \mathrm{T})$ 
A sequence of transitions $T$ of the transitional graph $G$ between two nodes (scenarios) $s_{1}$ and $s_{m}$ is called a directed path (shortly a path). The path starts in $s_{1}$ and ends in $s_{m}$. If $s_{1}=s_{m}$, the path is closed, otherwise the path is open. In this paper, closed paths are not the subject of our interest. The transitional graph is coherent if there is at least one path between its nodes. For more details about the graph theory see Gallier (2011). Any path of the transitional graph G represents a description of the trend and a prediction or past behaviour. This suggests that the transitional graph is a visualisation of all potential future or past events within the model. Hence, any prediction is equal to a choice of any path displayed within the transitional graph.

In this paper, the choice of a suitable path is based on the common sense heuristic: the more variables to change, the less probable this change becomes. Therefore, the paths with the least number of changed variables are searched.

\section{Data Description}

We adopt the case study approach, which is systematically interpreted as a way how qualitative research might be carried out when an in-depth investigation of complex phenomena is required (Harrison et al. 2017). The object of the case study is represented by two kinds of rumours. Both of them are spread through the web and other information channels. The first rumour concerns the institutional quality and we term this (F1). The second rumour is related to the internal state of the company and we term this (F2).

As noted above, (F1) is represented by a confounding amount of opinions, estimations and predictions concerning changes in macroeconomic policy in country A: The previous government left office and the new political leader repeatedly claimed during the pre-election political campaigns that institutional settings will be introduced to reduce risk and uncertainty to lead the economy to growth; positive effect on innovation and productivity are expected. Measures to favour the listing of young and innovative firms should be implemented to foster economic growth. This announcement has been extensively discussed and analysed by experts, market analysts and columnists in countless websites, chat rooms and forums as well as in economic sections of business journals. As reported by Spiegel et al. (2010) some rumours - accurate or fake - emerge and vanish very quickly, but other rumours become "multi-rumours" by being reproduced time and again.

If institutional improvements were introduced in the country's economy, it can be assumed that significant growth in investment will boost its economic output. An IPO strategy is more attractive as IPO candidates and investors are exposed to a lower degree of risk and uncertainty. A drop in transaction costs and an increase in returns on investment are likely to happen in relation to future developments. The volume of IPOs in the country "A" will increase because institutional and retail investors as well as firms' decision-makers will change their sentiment towards investments in newly issued shares and thus going public strategy. 
Contextual variables under study include two dimensions of institutional quality: 1) effectiveness of general economic institutions lowering the transaction cost, risk, and uncertainty (TC) and boosting returns on investment (r) (Kaufman et al. 2009) and 2) effectiveness of financial market institutions improving market liquidity (ML) and increasing IPO volumes (NIPO) in the country (La Porta et al. 2006, 1997). Four indices of governance proposed by Kaufman et al. (2009) are used to capture the following dimensions of general institutional quality: the government effectiveness (GEff), regulatory quality (Reg), rule of law (RoL), and control of corruption (Corr). Furthermore, two variables concentrated on the evaluation of institutional background in the local capital market are considered: regulatory and fiscal incentives to encourage institutional investors to enter the local capital market (IncInv) and regulatory incentives to attract emerging growth companies to conduct an IPO (IncIPO). All variables are lottery variables, i.e. both the investors and enterprises cannot take any action to influence them. For details see Table 1.

Table 1

Institutional settings affecting IPO market development - a description of the variables used

\begin{tabular}{|l|l|l|}
\hline \multicolumn{1}{|c|}{$\begin{array}{l}\text { Reneral Economic Institutions to Lower the Level of Transaction Costs }(T C) \text { and to Boost } \\
\text { Returns on Investment }(r)\end{array}$} \\
\hline $\begin{array}{l}\text { Government effectiveness } \\
\text { (Kaufman et al. 2009) }\end{array}$ & GEff & $\begin{array}{l}\text { Qualitative aspects of public services and the } \\
\text { extent of their independence from political } \\
\text { interests, the quality of policy conceptualization } \\
\text { and implementation, and the integrity of the } \\
\text { government's allegiance to such policies. }\end{array}$ \\
\hline $\begin{array}{l}\text { Regulatory quality (Kaufman } \\
\text { et al. 2009) }\end{array}$ & Reg & $\begin{array}{l}\text { The capability of the government to propose and } \\
\text { apply such a kind of policies and rules, which are } \\
\text { favourable to the development of non-public } \\
\text { sector. }\end{array}$ \\
\hline $\begin{array}{l}\text { Rule of law (Kaufman } \text { et al. } \\
\text { 2009) }\end{array}$ & $\begin{array}{l}\text { The scope to which market participants trust that } \\
\text { contracts and property rights are enforceable. The } \\
\text { economic agents also trust that the police as well } \\
\text { as the courts perform their functions. The } \\
\text { likelihood of crime and violence is also } \\
\text { considered. }\end{array}$ \\
\hline $\begin{array}{l}\text { Control of corruption } \\
\text { Kaufman et al. 2009) }\end{array}$ & Corr & $\begin{array}{l}\text { Perceptions of the degree to which public power } \\
\text { is misused for private benefit, including various } \\
\text { forms of corruption. }\end{array}$ \\
\hline
\end{tabular}

Financial Market Institutions to Improve Market Liquidity $(M L)$ and Increase the IPO Activity $(N I P O)$

\begin{tabular}{|lc|l|l|l|l} 
Regulatory and fiscal & IncInv & Incentives that aim in particular at the protection
\end{tabular} incentives to support the $\quad$ of minority shareholders and the expansion of the local capital market (La $\quad$ institutional investors' base.

Porta et al. 1997, Olgic Drazenovic and Kusanovic (2016) 


\begin{tabular}{|l|c|l|}
\hline $\begin{array}{l}\text { Regulatory incentives to } \\
\text { attract enterprises to conduct } \\
\text { an IPO (Wilson 2015) }\end{array}$ & $\begin{array}{c}\text { IncIP } \\
O\end{array}$ & $\begin{array}{l}\text { Incentives that aim at reducing regulatory and } \\
\text { reporting requirements to reduce compliance } \\
\text { costs. }\end{array}$ \\
\hline
\end{tabular}

Source: Kaufman et al. (2009), Olgic Drazenovic and Kusanovic (2016), Wilson (2015), La Porta et

al. (1997)

On the basis of the previous knowledge on the institutional determinants of the IPO activity in a country, the following variables and their relations, recorded by means of the pair relations from Figure 1, have been identified: P1(GEff, TC) $=$ 24; P2(Reg, TC) $=24 ; \mathrm{P} 3(\mathrm{RoL}, \mathrm{TC})=24 ; \mathrm{P} 4(\mathrm{Corr}, \mathrm{TC})=24 ; \mathrm{P} 5(\mathrm{TC}, \mathrm{r})=24$; $\mathrm{P} 6($ IncInv, ML $)=21 ; \mathrm{P} 7($ IncInv, TC $)=24 ; \mathrm{P} 8($ IncInv, NIPO $)=\mathrm{M}+; \mathrm{P} 9($ IncIPO, $\mathrm{TC})=24 ; \mathrm{P} 10(\mathrm{ML}, \mathrm{NIPO})=\mathrm{M}+; \mathrm{P} 11(\mathrm{IncIPO}, \mathrm{NIPO})=\mathrm{M}+; \mathrm{P} 12(\mathrm{ML}, \mathrm{TC})=24$.

\section{$\rightarrow$ Model QH1}

The M+ label is used if it cannot be said whether the speed of changes between the relevant variables is constant, increasing, or decreasing. Thus, $\mathrm{M}+$ stands for the relations 21, 22 and 23 given in Figure 1.

Moreover, in our case study rumours related to internal state of the company are considered (F2). These rumours are of a negative nature; hence, their spreading increases the uncertainty on the side of investors.

F2: There are misinformation and rumours about the firm's technology that is said not to be fully mature. Some experts, analysts, and stakeholders doubt the company would be able to achieve its full-year revenue targets and is actually not well prepared for the fund-raising process via IPO. These rumours seriously jeopardize the success of the primary issue which means "window of opportunity" might not remain open. Here, we define the "window of opportunity" as the most propitious time for launching an IPO. Here, it is a function of the firm's performance or exogenous factors (Loughran et al., 1994).

Ritter (1984) suggests that high profitability in previous periods is a significant factor encouraging managers to launch an IPO to gain from the window of opportunity. Pagano et al. (1998) contradicts this theory and believes that a negative relationship between profitability and the probability of going public (IPOP) exists as only firms that are incapable to produce sufficient internal resources prefer external capital. Alternative theories seem to attach little importance to the IPO timing hypothesis. The pecking-order theory assumes that firms prioritize internal to external financing because the cost of capital increases with information asymmetry (IA) between managers and external investors; this makes it extremely complicated to assess the prospects, risks, and value of a particular company (Myers 1984). Accordingly, retained profits (RP) are used first. When internal funds are depleted, bank loans (BL) represent the second financial choice. Issuing equity views the pecking-order theory as the last option. Other theories deal with the issue of how the information disclosure influences the decision to go public. Maksimovic and Pichler (2001) argue that a negative 
relationship exists between sensitivity to information disclosure, especially in $\mathrm{R} \& \mathrm{D}$ issues, and the probability of going public. Rajan (1992) suggests that raising capital via IPO can lower the price of bank loans, probably because firms improve the dissemination of information to stakeholders and consequently improve their bargaining power with banks. Chemmanur and Fulghiery (1999) notice that when an adequate amount of information about firms is publicly accesible, the costs of producing information (CPI) decrease. In sum, in the case of mature and well-established companies is the probability of an IPO higher. Investors may also assess an IPO as risky because insufficient historical public data on the issuing company is available. With the less predictable future cash flows and the lower liquidity, there is the higher underpricing (UP) of the issued shares. Investors have to be compensated for their risk related to information asymmetry.

On the basis of the previous knowledge, the following firm-specific variables have been identified: IA, RP, BL, IPOP, CPI, and UP. We suggest that all these variables are decision variables, i.e. both the investors and enterprises can take any action to influence their quality. Their relations recorded by means of the pair relations from Figure 1 are as follows: P13(IA, RP) $=22$; P14(IA, BL) $=\mathrm{M}+$; P15 (IA, UP $)=21 ;$ P16 (IA, CPI $)=22 ;$ P17 (IPOP, CPI $)=24$.

$\rightarrow$ Model QH2

\section{Qualitative Heuristics-Based Model}

We use the pair relations to formulate the qualitative models QH1 and QH2. Both of them are based on heuristics. Propagating the rumours F1 and F2 is described by the qualitative model $\mathrm{QR}$. This is derived from the SIRaRu rumour spreading model by Wang et al. (2014) and extended with the infection rate of the population by the rumour PP.

$\mathrm{DI}=-\mathrm{I} \cdot \mathrm{S}$

$\mathrm{DS}=+\mathrm{I} \cdot \mathrm{S}-\mathrm{S}(\mathrm{S}+\mathrm{Ra}+\mathrm{Ru})-\mathrm{S}$

$\mathrm{DRa}=\mathrm{I} \cdot \mathrm{S}+\mathrm{S}(\mathrm{S}+\mathrm{Ra}+\mathrm{Ru})+\mathrm{S}$

$\mathrm{DRu}=\mathrm{I} \cdot \mathrm{S}$

$P \_P=\left(S+R \_a\right) /\left(S+R \_a+R \_u+I\right)$

The impact of the rumour propagation onto the IPO may be described by suitably interconnecting the model QR (14) with the models QH1 (12) and QH2 (13). Interconnecting both models $\mathrm{QH}(1,2)$ and $\mathrm{QR}$ may be performed by means of introducing the additional pair relations, i.e. by introducing another on heuristicsbased qualitative model QH3. The coupling of the two rumours (F1 and F2) may cause contradictory reactions on the side of investors. Their decision to invest in newly issued stocks is either positive or negative and ultimately affect the success of the IPO. Accordingly, the heuristics $\mathrm{H} 2$ and $\mathrm{H} 3$ are as follows: 
(H2) The growing knowledge of the rumour F1, i.e. the growing infection rate of the population PP, will lower transaction cost (TC). This will increase the IPO activity (NIPO) in the country and thus the probability of going public (IPOP). (H3) The growing knowledge of the rumour F2, i.e. the growing infection rate of the population PP, will increase the cost of producing information (CPI). This will dampen the probability of going public (IPOP).

The heuristics $\mathrm{H} 2$ does not conclusively indicate the changes in the speed of the transaction cost (TC) as the population infection rate PP grows. This means that the relation 24 or 25 or 26 (see Figure 1) may be used to describe the relationship between the TC and PP. These possible potential links will be marked by the label M-. Similarly, the heuristics H3 formulation does not conclusively indicate the changes in the speed of the cost of producing information (CPI) as the population infection rate PP grows. This means that the relation 21 or 22 or 23 (see Figure 1) may be used for the purposes of expressing the relation between the CPI and PP. These possible mutual links will be represented by the label M+. In such a case, the heuristics $\mathrm{H} 2$ and $\mathrm{H} 3$ may be recorded by the pair relations as follows: $\mathrm{P} 14(\mathrm{PP}, \mathrm{TC})=\mathrm{M}-; \mathrm{P} 15(\mathrm{PP}, \mathrm{CPI})=\mathrm{M}+$. These pair relations are represented by the qualitative model $\mathrm{QH} 2$, which is derived from heuristics $\mathrm{H} 2$ and $\mathrm{H} 3$.

The model characterizing the rumour spreading and its impact onto the IPO is an outcome of combining the models $\mathrm{QH} 1, \mathrm{QR}$ and $\mathrm{QH} 2$. The resulting model is a mixed qualitative model QS.

$\mathrm{QS}=\mathrm{QH} 1 \vee \mathrm{QR} \vee \mathrm{QH} 2$

\section{Research Results}

A total of 46 possible transitions between all 9 scenarios could be identified (Table 2). These scenarios and their transitions are shown in the graph G (Figure 2). The initial node is denoted as 1 and the terminal node is denoted as 9. Each edge of the transitional graph represents the transition from one node to another. This transition is associated with a certain amount of time expressed in certain time units. The graph represents an overview of all possible oriented paths between the individual nodes/scenarios. These oriented paths are of a qualitative nature and describe the past and future behaviour of the model or variables under study. Therefore, any forecast concerning institutional determinants or the internal state of the company is equivalent equal to a path through a transitional graph. This means that any efforts to predict the future behaviours, which belong to the most common tasks of decision-makers, might be solved while using the graph. These predictions are done by rationally thinking participants assessing individual going public and investment strategies (decision-makers, such as the CFOs of issuing company, investors, columnists, social media contributors, etc.). 
Table 2

A list of all one-dimensional transition

\begin{tabular}{|c|c|c|c|c|c|c|c|c|c|c|c|c|c|c|c|c|}
\hline & $\frac{A}{x}$ & 胥 & 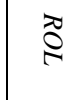 & 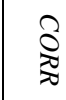 & $\vec{n}$ & $\gtrless$ & ß & $\geqq$ & $\geqq$ & 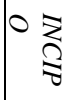 & $\bar{\Delta}$ & $\vec{\sigma}$ & $\infty$ & 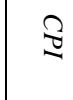 & $\mathbb{\nabla}$ & 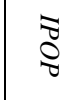 \\
\hline 1 & ++ & +++ & ++- & ++0 & +-+ & ++0 & ++- & ++- & ++- & ++- & +-+ & +-+ & +-+ & +-+ & +-+ & ++0 \\
\hline 2 & +++ & ++0 & ++- & ++0 & +-+ & ++0 & ++- & ++- & ++- & ++- & +-+ & +-+ & +-+ & +-+ & +-+ & ++0 \\
\hline 3 & +++ & 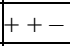 & ++- & ++0 & +-+ & ++0 & + & ++- & 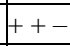 & ++- & +-+ & +-+ & +-+ & +-+ & +-+ & ++0 \\
\hline 4 & ++0 & ++ & +- & ++0 & +-+ & ++0 & + & +- & ++ & ++- & +-+ & +-+ & +-+ & +-+ & +-+ & ++0 \\
\hline 5 & ++0 & ++0 & ++- & ++0 & +-+ & ++0 & ++- & ++- & ++ & ++- & +-+ & +-+ & +-+ & +-+ & +-+ & ++0 \\
\hline 6 & ++0 & ++ & ++- & ++0 & +-+ & ++0 & ++- & ++- & ++- & ++- & +-+ & +-+ & +-+ & +-+ & +-+ & ++0 \\
\hline 7 & ++- & + & ++- & ++0 & +-+ & ++0 & 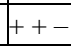 & ++- & ++- & ++- & +-+ & +-+ & +-+ & +-+ & +-+ & ++0 \\
\hline 8 & ++- & +0 & ++- & ++0 & +-+ & ++0 & ++- & ++- & ++- & ++- & +-+ & +-+ & +-+ & +-+ & +-+ & ++0 \\
\hline & & & 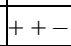 & ++0 & 1 & ++0 & 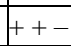 & ++ & 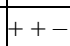 & 1 & +-+ & +-+ & +-+ & +-+ & +-+ & ++0 \\
\hline
\end{tabular}

Source: created by the authors

In sum, we identified 235 paths; an example of them is shown in Table 3. Each transition between scenarios is associated with changing at least one variable. Based on the number of variables to be changed, the paths with the least number of variables are selected from 235 paths. There were 13 paths selected (Table 4). Four variables were changed on these paths. Analogously, it is also possible to derive a trend graph for the other variables. Based on Table 3, it is possible to forecast the development of individual variables over time. For instance, Figure 3 shows the development of the variable REG over time $t$.

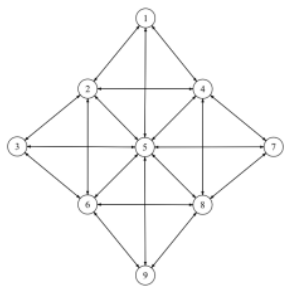

Figure 2

Transitional graph G

Source: created by the authors.

Table 3

A non-comprehensive list of paths

\begin{tabular}{|l|l||l|l|}
\hline No & Path & No & Path \\
\hline \hline 1 & $1 \rightarrow 2 \rightarrow 3 \rightarrow 5 \rightarrow 4 \rightarrow 7 \rightarrow 8 \rightarrow 6 \rightarrow 9$ & $\vdots$ & \\
\hline 2 & $1 \rightarrow 2 \rightarrow 3 \rightarrow 5 \rightarrow 4 \rightarrow 7 \rightarrow 8 \rightarrow 9$ & 220 & $1 \rightarrow 5 \rightarrow 7 \rightarrow 4 \rightarrow 2 \rightarrow 3 \rightarrow 6 \rightarrow 9$ \\
\hline 3 & $1 \rightarrow 2 \rightarrow 3 \rightarrow 5 \rightarrow 4 \rightarrow 8 \rightarrow 6 \rightarrow 9$ & 221 & $1 \rightarrow 5 \rightarrow 7 \rightarrow 4 \rightarrow 2 \rightarrow 6 \rightarrow 8 \rightarrow 9$ \\
\hline 4 & $1 \rightarrow 2 \rightarrow 3 \rightarrow 5 \rightarrow 4 \rightarrow 8 \rightarrow 9$ & 222 & $1 \rightarrow 5 \rightarrow 7 \rightarrow 4 \rightarrow 2 \rightarrow 6 \rightarrow 9$ \\
\hline 5 & $1 \rightarrow 2 \rightarrow 3 \rightarrow 5 \rightarrow 6 \rightarrow 8 \rightarrow 9$ & 223 & $1 \rightarrow 5 \rightarrow 7 \rightarrow 4 \rightarrow 8 \rightarrow 6 \rightarrow 9$ \\
\hline
\end{tabular}




\begin{tabular}{|l|l||l|l|}
\hline 6 & $1 \rightarrow 2 \rightarrow 3 \rightarrow 5 \rightarrow 6 \rightarrow 9$ & 224 & $1 \rightarrow 5 \rightarrow 7 \rightarrow 4 \rightarrow 8 \rightarrow 9$ \\
\hline 7 & $1 \rightarrow 2 \rightarrow 3 \rightarrow 5 \rightarrow 7 \rightarrow 4 \rightarrow 8 \rightarrow 6 \rightarrow 9$ & 225 & $1 \rightarrow 5 \rightarrow 7 \rightarrow 8 \rightarrow 4 \rightarrow 2 \rightarrow 3 \rightarrow 6 \rightarrow 9$ \\
\hline 8 & $1 \rightarrow 2 \rightarrow 3 \rightarrow 5 \rightarrow 7 \rightarrow 4 \rightarrow 8 \rightarrow 9$ & 226 & $1 \rightarrow 5 \rightarrow 7 \rightarrow 8 \rightarrow 4 \rightarrow 2 \rightarrow 6 \rightarrow 9$ \\
\hline 9 & $1 \rightarrow 2 \rightarrow 3 \rightarrow 5 \rightarrow 7 \rightarrow 8 \rightarrow 6 \rightarrow 9$ & 227 & $1 \rightarrow 5 \rightarrow 7 \rightarrow 8 \rightarrow 6 \rightarrow 9$ \\
\hline 10 & $1 \rightarrow 2 \rightarrow 3 \rightarrow 5 \rightarrow 7 \rightarrow 8 \rightarrow 9$ & 228 & $1 \rightarrow 5 \rightarrow 7 \rightarrow 8 \rightarrow 9$ \\
\hline 11 & $1 \rightarrow 2 \rightarrow 3 \rightarrow 5 \rightarrow 8 \rightarrow 6 \rightarrow 9$ & 229 & $1 \rightarrow 5 \rightarrow 8 \rightarrow 4 \rightarrow 2 \rightarrow 3 \rightarrow 6 \rightarrow 9$ \\
\hline 12 & $1 \rightarrow 2 \rightarrow 3 \rightarrow 5 \rightarrow 8 \rightarrow 9$ & 230 & $1 \rightarrow 5 \rightarrow 8 \rightarrow 4 \rightarrow 2 \rightarrow 6 \rightarrow 9$ \\
\hline 13 & $1 \rightarrow 2 \rightarrow 3 \rightarrow 5 \rightarrow 9$ & 231 & $1 \rightarrow 5 \rightarrow 8 \rightarrow 6 \rightarrow 9$ \\
\hline 14 & $1 \rightarrow 2 \rightarrow 3 \rightarrow 6 \rightarrow 5 \rightarrow 4 \rightarrow 7 \rightarrow 8 \rightarrow 9$ & 232 & $1 \rightarrow 5 \rightarrow 8 \rightarrow 7 \rightarrow 4 \rightarrow 2 \rightarrow 3 \rightarrow 6 \rightarrow 9$ \\
\hline 15 & $1 \rightarrow 2 \rightarrow 3 \rightarrow 6 \rightarrow 5 \rightarrow 4 \rightarrow 8 \rightarrow 9$ & 233 & $1 \rightarrow 5 \rightarrow 8 \rightarrow 7 \rightarrow 4 \rightarrow 2 \rightarrow 6 \rightarrow 9$ \\
\hline 16 & $1 \rightarrow 2 \rightarrow 3 \rightarrow 6 \rightarrow 5 \rightarrow 7 \rightarrow 4 \rightarrow 8 \rightarrow 9$ & 234 & $1 \rightarrow 5 \rightarrow 8 \rightarrow 9$ \\
\hline$\vdots$ & $\ldots \vdots$ & 235 & $1 \rightarrow 5 \rightarrow 9$ \\
\hline
\end{tabular}

Source: own calculations.

Table 4

Paths with the least number of variables to be changed

\begin{tabular}{|l|l||l||l||}
\hline No & Path & No & Path \\
\hline \hline 1 & $1 \rightarrow 2 \rightarrow 3 \rightarrow 6 \rightarrow 9$ & 8 & $1 \rightarrow 4 \rightarrow 5 \rightarrow 9$ \\
\hline 2 & $1 \rightarrow 2 \rightarrow 5 \rightarrow 6 \rightarrow 9$ & 9 & $1 \rightarrow 4 \rightarrow 7 \rightarrow 8 \rightarrow 9$ \\
\hline 3 & $1 \rightarrow 2 \rightarrow 5 \rightarrow 8 \rightarrow 9$ & 10 & $1 \rightarrow 4 \rightarrow 8 \rightarrow 9$ \\
\hline 4 & $1 \rightarrow 2 \rightarrow 5 \rightarrow 9$ & 11 & $1 \rightarrow 5 \rightarrow 6 \rightarrow 9$ \\
\hline 5 & $1 \rightarrow 2 \rightarrow 6 \rightarrow 9$ & 12 & $1 \rightarrow 5 \rightarrow 8 \rightarrow 9$ \\
\hline 6 & $1 \rightarrow 4 \rightarrow 5 \rightarrow 6 \rightarrow 9$ & 13 & $1 \rightarrow 5 \rightarrow 9$ \\
\hline 7 & $1 \rightarrow 4 \rightarrow 5 \rightarrow 8 \rightarrow 9$ & & \\
\hline
\end{tabular}

Source: own calculations.

Figure 3 is not a conventional graph, but a trend graph. The following inequalities represent the only restrictions:

$0<\mathrm{a}<\mathrm{b}<\mathrm{c}$

The numerical values of intervals are not relevant.

\section{Conclusions}

In this paper, we investigated the propagation of rumours in complex social networks and their impact on going public activity in a country while using the SIRaRu rumour propagation model and qualitative trend-based techniques. The qualitative research concept has been applied to study the propagation of rumours (Meluzín et al. 2018). Rumours might be described as unique, partially subjective, inconsistent, vague and multidimensional. Oversimplified and/or exact quantitative models can deliver misleading results. The main explanation of this phenomenon is a serious lack of data (Doubravsky et al. 2020). 


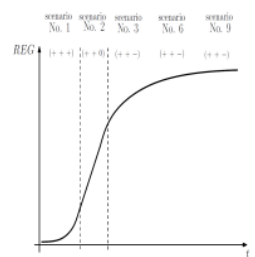

Path 1

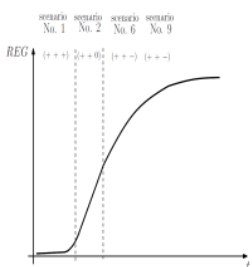

Path 5

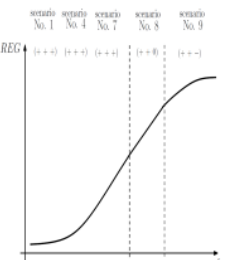

Path 9

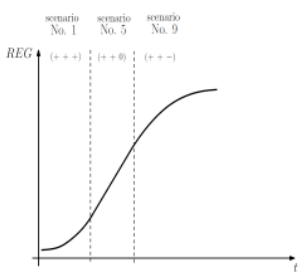

Path 13

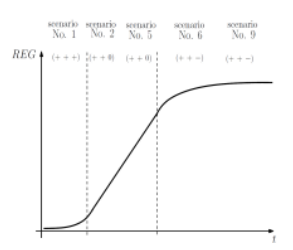

Path 2

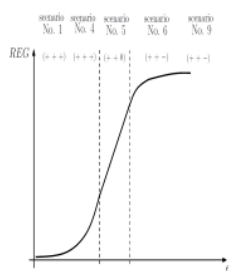

Path 6

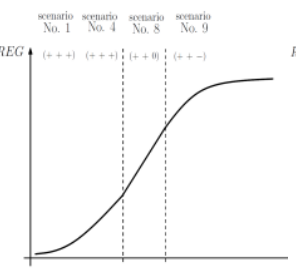

Path 10

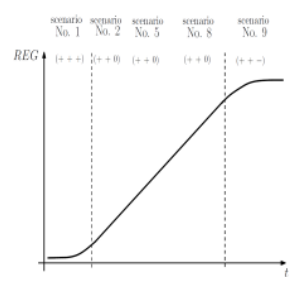

Path 3

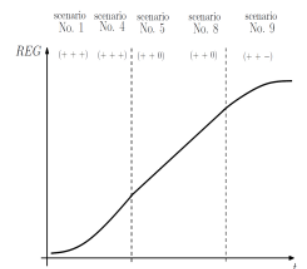

Path 7

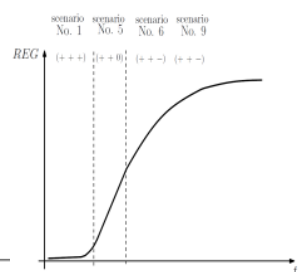

Path 11

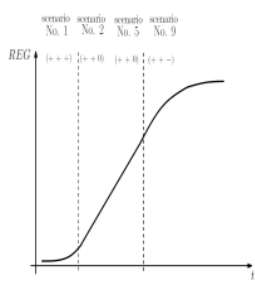

Path 4

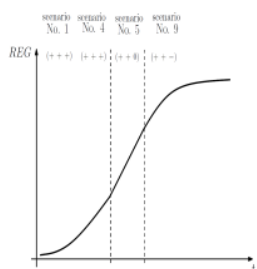

Path 8

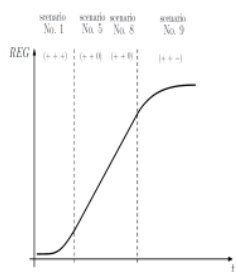

Path 12

Figure 3

Qualitative description of the function REG(t)

Source: created by the authors.

Here, we document for the first time how two kinds of rumours - the first one is positive, the second one negative - might be spread and consequently support or dampen the development of the IPO market in a country. The positive rumour is out of control of decision-makers (we call this a lottery), while the negative rumour might be controlled by market participants. The main research outputs consist in a qualitative heuristics-based model and in a transitional graph. 
Furthermore, we derived a graphical solution to investigate the evolution of the investigated variables over time. The set of scenarios, the transitional graph and the visualization of the development of variables represent a comprehensive tool allowing managers of issuing companies, investors, and other market participants to better understand the relationship between monitored variables. Based on the results, the whole variety of past or future developments of the variables under study can be analysed. Hence, the users of the model can derive how an individual variable can be affected by changing other variables. For instance, how law enforcement in the country will change if government effectiveness and corruption control will increase, but the growth of these variables will slow down.

There are five main benefits of the qualitative approach in the research of rumour propagation. Firstly, no numerical inputs about levels of measurements are required and the set of qualitative solutions represents a superset of all relevant solutions. This means that no significant forecast can be excluded. Secondly, all available time transitions among the obtained set of scenarios are specified. Thirdly, the very nature of the model enables studying its inner dynamics. Alternative variables can be integrated into the model. This feature makes it very flexible in performing any union or intersection of different models. Finally, the approach results are based on expert estimates and common sense, which makes them comprehensible from the perspective of practitioners. Corporate managers, investors, and other stakeholders are provided with a flexible tool to support effective decision-making without the knowledge of sophisticated mathematical and statistical methods. On the other hand, the disadvantages of qualitative models cannot be neglected. The most important of them consists in the linearity assumption (Doubravsky a Dohnal 2018, Doubravsky et al. 2020).

In the follow-up research, efforts will be made to improve the stability and accuracy of the model under study. Furthermore, probabilities of future forecasts and scenarios will be quantified while using the topology of the transitional graphs.

\section{Funding}

This work was supported by the Institute of Economic Research, Poland, and Brno University of Technology, Faculty of Business and Management, Czech Republic (grant number 2019/1). The title of the project is "Public and Private Equity in CEE countries".

\section{References}

[1] Balcerzak, A. P. (2020) Quality of institutions in the European Union countries. Application of TOPSIS based on entropy measure for objective weighting. Acta Polytechnica Hungarica, 17(1), 101-122, doi: https://doi.org/10.12700/APH.17.1.2020.1.6 
[2] Balcerzak, A. P., Pietrzak, M. B. (2017) Digital Economy in Visegrad Coutnries. Multiple-criteria decision analysis at Regional Level in the Years 2012 and 2015. Journal of Competitiveness, 9(2), 5-18

[3] Bonaventura, M., \& Giudici, G. (2017) IPO valuation and profitability expectations: evidence from the Italian exchange. Eurasian Business Review, 7(2), 247-266

[4] Boot, A. W. A., Gopalan, R., \& Thakor, A. V. (2006) The Entrepreneur's Choice between Private and Public Ownership . Journal of Finance, 61(2), 803-836, https://doi.org/10.1111/j.1540-6261.2006.00855.x

[5] Chemmanur, T. J., \& Fulghieri, P. (1999) A Theory of the Going-Public Decision. Review of Financial Studies, 12(2), 249-279, https://doi.org/10.1093/rfs/12.2.249

[6] Chen, C. -Da, \& Kutan, A. M. (2016) Information Transmission Through Rumors in Stock Markets: A New Evidence. The Journal Of Behavioral Finance, 17(4), 365-381, https://doi.org/10.1080/15427560.2016.1238373

[7] Certo, S., Holcomb, T. R., \& Holmes, R. M. (2009) IPO research in management and entrepreneurship: Moving the agenda forward. Journal of Management, 35(6), 1340-1378, https://doi.org/10.1177/ 0149206309347375

[8] Daley, D. J., Kendall, D. G. (1964) Epidemics and Rumours. Nature, 204(1118), 42-55

[9] Djankov, S., La Porta, R., Lopez-de-Silanes, F., \& Shleifer, A. (2008) The law and economics of self-dealing . Journal of Financial Economics, 88(3), 430-465, https://doi.org/10.1016/j.jfineco.2007.02.007

[10] Doidge, C., Karolyi, G., \& Stulz, R. (2012) Financial Globalization and the Rise of IPOs outside the U.S. Ideas Working Paper Series From Repec. http://search.proquest.com/docview/1698269929/

[11] Doubravsky, K., \& Dohnal, M. (2018) Qualitative equationless macroeconomic models as generators of all possible forecasts based on three trend values - Increasing, constant, decreasing. Structural Change and Economic Dynamics, 45, 30-36, https://doi.org/10.1016/ j.strueco.2018.01.001

[12] Doubravsky, K., Doskocil, R., \& Dohnal, M. (2020) A Dynamic Knowledge Model of Project Time-Cost Analysis Based on Trend Modelling. Periodica Polytechnica Social and Management Sciences, 28(1), 18-28, https://doi.org/10.3311/PPso.13318

[13] Foley, C. F., \& Greenwood, R. (2010) The Evolution of Corporate Ownership after IPO: The Impact of Investor Protection. The Review Of Financial Studies, 23(3), 1231-1260. https://doi.org/10.1093/rfs/hhp069 
[14] Fontinelle, A. (2015) IPO vs. Staying Private: Pros \& Cons of Each Model. Investopedia, September 1

[15] Gallier, J. (2011) Discrete Mathematics. New York: Springer Science+Business Media. https:/doi.org/10.1007/978-1-4419-8047-2

[16] Goffman, W., \& Newill, V. A. (1964) Generalization of Epidemic Theory. An Application to the Transmission of Ideas. Nature, 17, 225-228

[17] Gombola, M., Liu, F. -Ying, \& Chou, D. -Wai. (2019) Capital structure dynamics with restricted equity issuance: Evidence from Chinese post-IPO firms. Asia Pacific Management Review, 24(1), 72-85, https://doi.org/10.1016/j.apmrv.2018.07.002

[18] Harrison, H., Birks, M., Franklin, R., \& Mills, J. (2017) Case Study Research: Foundations and Methodological Orientations. Forum Qualitative Sozialforschung / Forum: Qualitative Social Research, 18(1), doi:http://dx.doi.org/10.17169/fqs-18.1.2655

[19] Helmke, G., \& Levitsky, S. (2004) Informal Institutions and Comparative Politics: A Research Agenda. Perspectives on Politics, 2(4), 725-740

[20] Hlel, K., Kahloul, I., \& Bouzgarrou, H. (2020) IFRS adoption, corporate governance and management earnings forecasts. Journal of Financial Reporting \& Accounting, 18(2), 325-342, https://doi.org/10.1108/JFRA-012019-0007

[21] Huang, J., \& Jin, X. (2011) Preventing rumor spreading on small-world networks. Journal of Systems Science and Complexity, 24(3), 449-456, https://doi.org/10.1007/s11424-011-8303-1

[22] Jiang, P., Zhou, Q., Jiang, H., \& Yao, D. (2014) An Optimized Forecasting Approach Based on Grey Theory and Cuckoo Search Algorithm: A Case Study for Electricity Consumption in New South Wales. Abstract and Applied Analysis, 2014 (2014) https://doi.org/10.1155/2014/183095

[23] Karkowska, R., \& Kravchuk, I. (2019) Identification of global systemically important stock exchanges. Equilibrium. Quarterly Journal of Economics and Economic Policy, 14(1), 31-51, https://doi.org/10.24136/eq.2019.002

[24] King, R., G., \& Levine, R. (1993) Finance and growth: Schumpeter might be right (English). Policy, Research working papers; no. WPS 1083, Financial policy and systems. Washington, DC: World Bank

[25] Kiseláková, D., Šofranková, B., Onuferová, E., \& Čabinová, V. (2019) The evaluation of competitive position of EU-28 economies with using global multi-criteria indices. Equilibrium. Quarterly Journal of Economics and Economic Policy, 14(3), 441-462, https://doi.org/10.24136/eq.2019.021

[26] Kliestik, T., Valaskova, K., Nica, E., Kovacova, M., \& Lazaroiu, G. (2020) Advanced methods of earnings management: monotonic trends and change- 
points under spotlight in the Visegrad countries. Oeconomia Copernicana, 11(2), 371-400, https://doi.org/10.24136/oc.2020.016

[27] Kosfeld, M. (2005) Rumours and markets . Journal of Mathematical Economics, 41(6), 646-664, https://doi.org/10.1016/j.jmateco.2004.05.001

[28] La Porta, R., Lopez-de-Silanes, F., Shleifer, A., \& Vishny, R. W. (1997) Legal Determinants of External Finance, Journal of Finance, 52(3), https://doi.org/10.1111/j.1540-6261.1997.tb02727.x

[29] La Porta, R., Lopez-de-Silanes, F., \& Shleifer, A. (2006) What Works in Securities Laws? Journal Of Finance, 61(1), 1-32, https://doi.org/ 10.1111/j.1540-6261.2006.00828.x

[30] Lewellyn, K. B., \& Bao, S. 'Rosey'. (2014) A cross-national investigation of IPO activity: The role of formal institutions and national culture. International Business Review, 23(6), 1167-1178, https://doi.org/10.1016/ j.ibusrev.2014.03.010

[31] Lizińska, W., Marks-Bielska, R., Babuchowska, K., \& Wojarska, M. (2016) Institutional efficiency of local government in issuing administrative decisions, exemplified by the performance of the local government appeal board in Olsztyn. Oeconomia Copernicana, 7(2), 285-296, https://doi.org/ 10.12775/OeC.2016.017

[32] Loughran, T., Ritter, J. R., \& Rydqvist, K. (1994) Initial public offerings: International insights. Pacific-Basin Finance Journal, 2(2), 165-199, https://doi.org/10.1016/0927-538X(94)90016-7

[33] Meluzín, T., Balcerzak, A., Pietrzak, M., Zinecker, M., \& Doubravsky, K. (2018) The Impact of Rumours Related to Political and Macroeconomic Uncertainty on IPO Success: Evidence from a Qualitative Model. Transformations in Business \& Economics, 17 2(44), 148-169

[34] Maksimovic, V., \& Pichler, P. (2001) Technological Innovation and Initial Public Offerings. Review of Financial Studies, 14(2), 459-494, https://doi.org/10.1093/rfs/14.2.459

[35] Myers, S. C. (1984) The Capital Structure Puzzle. Journal of Finance, 39(3), 575-592, https://doi.org/10.1111/j.1540-6261.1984.tb03646.x

[36] Nekovee, M., Moreno, Y., Bianconi, G., \& Marsili, M. (2007) Theory of rumour spreading in complex social networks. Physica A: Statistical Mechanics and Its Applications, 374(1), 457-470, https://doi.org/10.1016/ j.physa.2006.07.017

[37] North, D. (2003) The Role of Institutions in Economic Development. Ideas Working Paper Series From Repec. Retrieved from http://search.proquest.com/docview/1698318593/ 
[38] North, D. C. (1990) Institutions, institutional change and economic performance. New York: Cambridge University Press, https:/doi.org/ 10.1017/CBO9780511808678

[39] Olbryś, J. (2019) Intra-market commonality in liquidity: new evidence from the Polish stock exchange. Equilibrium. Quarterly Journal of Economics and Economic Policy, 14(2), 251-275, https://doi.org/10.24136/eq.2019.01

[40] Olgic Drazenovic, B., \& Kusanovic, T. (2016) Determinants of capital market in the new member EU countries. Ekonomska Istrazivanja, 29(1), 758-769, https://doi.org/10.1080/1331677X.2016.1197551

[41] Pagano, M., Panetta, F., \& Zingales, L. (1998) Why Do Companies Go Public? An Empirical Analysis. Journal of Finance, 53(1), 27-64, https://doi.org/10.1111/0022-1082.25448

[42] Pieloch-Babiarz, A. (2020) Managerial ownership and catering to investor sentiment for dividends: evidence from the electromechanical industry sector on the Warsaw Stock Exchange. Oeconomia Copernicana, 11(3), 467-483, https://doi.org/10.24136/oc.2020.019

[43] Rajan, R. G. (1992) Insiders and Outsiders: The Choice between Informed and Arm's-Length Debt. Journal of Finance, 47(4), 1367-1400, https://doi.org/10.1111/j.1540-6261.1992.tb04662.x

[44] Ritter, J. (1984) The "Hot Issue" Market of 1980. The Journal of Business, 57(2), 215, https://doi.org/10.1086/296260

[45] Skare, M., \& Porada-Rochoń, M. (2019) Tracking financial cycles in ten transitional economies 2005-2018 using singular spectrum analysis (SSA) techniques. Equilibrium. Quarterly Journal of Economics and Economic Policy, 14(1), 7-29, https://doi.org/10.24136/eq.2019.001

[46] Spiegel, U., Tavor, T., \& Templeman, J. (2010) The effects of rumours on financial market efficiency. Applied Economics Letters, 17(15), 14611464, https://doi.org/10.1080/13504850903035873

[47] Wang, J., Zhao, L., \& Huang, R. (2014) SIRaRu rumor spreading model in complex networks . Physica A: Statistical Mechanics and its Applications, 398, 43-55, https://doi.org/10.1016/j.physa.2013.12.004

[48] Yan, X., Zhou, Y., Wen, Y., \& Chai, X. (2013) Qualitative and Quantitative Integrated Modeling for Stochastic Simulation and Optimization. Journal Of Applied Mathematics, $2013 \quad$ (2013) https://doi.org/10.1155/2013/831273 